\title{
O PROCESSAMENTO DA ANÁFORA “SE” EM PORTUGUÊS BRASILEIRO E A
} INFLUÊNCIA DA VARIAÇÃO DIALETAL

\author{
EL PROCESAMIENTO DE LA ANÁFORA “SE” EN PORTUGUÉS BRASILEÑO Y LA INFLUENCIA DE LA \\ VARIACIÓN DIALECTAL
}

\author{
THE PROCESSING OF BRAZILIAN PORTUGUESE ANAPHORA AND THE INFLUENCE OF DIALECTAL \\ VARIATION
}

\author{
Maria Cláudia Mesquita Lacerda* \\ Rosana Costa de Oliveira** \\ Márcio Martins Leitão*** \\ Universidade Federal da Paraíba - UFPB, João Pessoa, BR
}

\begin{abstract}
RESUMO: O objetivo desta pesquisa foi investigar se diferentes tipos de retomada [se, $\emptyset$, ele $(a)]$ podem influenciar o processamento correferencial de estruturas reflexivas, relacionando a estas a semântica do predicado verbal. Para verificar se a variação dialetal do uso da anáfora se (uso, supressão, e substituição) poderia influenciar o processamento destas estruturas, foi realizado um experimento de leitura automonitorada em Minas Gerais e Paraíba. Os resultados evidenciaram um efeito significativo do tipo de retomada, indicando a possibilidade da influência de tipo de verbo. Acredita-se que as restrições sintáticas da teoria da ligação (CHOMSKY, 1981) foram ativadas em estágios iniciais de processamento (NICOL; SWINNEY, 1989), entretanto a interpretabilidade a partir da semântica verbal e a questão discursiva relacionada a fatores de uso (variação) fez com que houvesse uma reanálise pelo parser.
\end{abstract}

PALAVRAS-CHAVE: Processamento linguístico; Teoria da Ligação; anáfora; variação dialetal.

RESUMEN: El objetivo de este trabajo fue investigar si los diferentes tipos de recuperación del Portugués de Brasil [se, Ø, ele (a)」 pueden influir en el tratamiento del pronombre reflexivo correferencial, bajo la influencia de la semántica del predicado verbal. Para comprobar también si la variación dialectal del pronombre reflexivo "se" (uso, omisión y sustitución) podría influir en el tratamiento de estas estructuras reflexivas, hicimos un experimento de lectura a su propio ritmo (self-paced reading test) en dos distintas regiones brasileñas, Minas Gerais y Paraíba. Los resultados mostraron un efecto significativo en el tipo de recuperación, lo que sugiere la posible influencia por el tipo de verbo. En general, los resultados indican un tratamiento inicial (NICOL; SWINNEY, 1989) de las restricciones sintácticas de la Teoría del Ligamiento (CHOMSKY, 1981), pero también encontramos un procesamiento tardío, probablemente debido a las diversas posibilidades de interpretación de la semántica de los verbos y a la variación discursiva, lo que sugiere que hubo un nuevo análisis por el parser.

PALABRAS CLAVE: Procesamiento del Lenguaje; Teoría de la conexión; la anáfora; la variación dialectal.

ABSTRACT: The objective of this research was to investigate whether different types of recovery [se, $\varnothing$, ele(a)] may influence the coreferential processing of reflective structures, relating to these, the semantics of the verbal predicate. To verify whether the dialectal variation of the use of anaphora "se" (use, removal, and replacement) could influence the processing of these structures, we performed a self-paced reading experiment in Minas Gerais and Paraíba. The results showed a significant effect on the type of retrieval, indicating the possibility of the influence of verb type. It is believed that syntactic constraints of the Binding theory (Chomsky, 1981) were activated in early stages of processing (NICOL; SWINNEY, 1989), however, the interpretability from the verbal semantics and the discursive question related to usage factors (range) meant that there was a re-examination by the parser.

KEYWORDS: Language Processing; Binding Theory; anaphora; dialectal variation.

\section{INTRODUÇÃO}

Diversos estudos sobre o processamento linguístico têm buscado a partir de diferentes técnicas experimentais, demonstrar se somente os fatores sintáticos/estruturais determinariam a escolha/ ligação da anáfora a um antecedente. A Teoria da Ligação (Binding Theory, CHOMSKY, 1981) seria a responsável por definir as restrições sintáticas que permitem a identificação de antecedentes gramaticais de pronomes, anáforas e outras expressões referenciais na compreensão de sentenças. Os fatores sintáticos, então, seriam os responsáveis por identificar a possibilidade ou não de realizar a ligação dessas expressões durante a resolução da correferência.

\footnotetext{
* Mestre em Linguística / PROLING - UFPB / membro do Laboratório de Processamento Linguístico da UFPB (LAPROL - UFPB). Email: lacerdamariaclaudia@gmail.com.

*** Professora Adjunta II / Pesquisadora do Laboratório de Processamento Linguístico da UFPB (LAPROL-UFPB).

**** Professor Adjunto IV / Coordenador do Laboratório de Processamento Linguístico da UFPB (LAPROL-UFPB).
} 
Na literatura, em estudos em língua inglesa (NICOL; SWINNEY, 1989; CLIFTON, KENNISON; ALBRECHT, 1997; BADECKER; STRAUB, 2002; STURT, 2003; KENNISON, 2003), geralmente é assumido que a escolha do referente de uma anáfora, como himself (a si mesma), é especificada pela configuração estrutural obedecendo às restrições da Binding Theory de Chomsky (1981).

Em contraste, existem estudos que sugerem que a informação não estrutural/semântica parece desempenhar um papel determinante da resolução de referência, especialmente quando a forma referencial e seu referente estão em diferentes orações. Muitos pesquisadores têm argumentado que a informação semântica influencia a interpretação de anáforas e pronomes, assim como outros fatores de discurso (por exemplo, coerência, em WOLF et al., 2004). Talvez a resolução de anáfora não seja determinada por uma única restrição, mas sim por ser o resultado da interação de várias restrições (KAISER, 2003; KAISER; TRUESWELL, 2008).

Diante de muitas divergências sobre como as informações estruturais são usadas durante a resolução da correferência, e, embora a Teoria de Ligação tenha sido intensamente estudada por teóricos sintáticos, poucos trabalhos têm considerado seu papel no processamento online em Português Brasileiro. Então, neste estudo, procurou-se observar se fatores sintáticos e semânticos podem influenciar o processamento do pronome reflexivo se (doravante, anáfora se 1). Além disso, com base em estudos de outras vertentes linguísticas, observou-se o comportamento dessa variável anafórica em duas comunidades linguísticas (Minas Gerais e Paraíba).

A variação dialetal da anáfora se, processo em que a construção pronominalizada compete com a construção não pronominalizada, particularmente no dialeto mineiro, é amplamente estudada em pesquisas de outras vertentes linguísticas (D’ALBUQUERQUE, 1984; NUNES, 1995; 1996; ROCHA, 1999; CAMACHO, 2003; OLIVEIRA, 2006; CARVALHO, 2008; RIBEIRO, 2010). O pronome se em Português Brasileiro, segundo esses trabalhos, pode apresentar variação pela supressão(1), neutralização(2), inserção(3) ou duplicação(4). Segundo Oliveira (2006), o apagamento do se ocorreria em Minas Gerais, a neutralização seria um fenômeno nacional, e a inserção e a “duplicação” do se seria característica do Nordeste.

(1) Eu _ conformei com a decisão dele.

(2) Eu se conformei com a decisão dele.

(3) Ele $\boldsymbol{s e}$ ressuscitou.

(4) Ela se conformou-se com a decisão dele

Camacho (2003), a partir dos achados de Lemle (1985) que reporta dados presentes na tese de Silva (1984), considera que haveria evidências de que em algumas variedades dialetais, comandadas pelo dialeto mineiro, possa haver a substituição da anáfora se por um pronome lexical (ele(a)). Entretanto, para Galves (2001), o pronome ele, em (5) apresenta leitura correferente por remeter ao tópico discursivo e não por haver reflexividade com o sujeito. Ambos, João e ele remeteriam a mesma pessoa, o tópico discursivo.

(5) João viu ele no espelho.

Diante do exposto, o presente estudo experimental, a partir da técnica de leitura automonitorada, tem como objetivo investigar se diferentes tipos de retomada [se, $\varnothing$, ele(a) $]$ podem influenciar o processamento correferencial de estruturas reflexivas. Pretende-se também observar se a semântica do predicado verbal (como prováveis reflexivos e prováveis não reflexivos) pode influenciar o processamento das anáforas. Além disso, planeja-se verificar se diferenças dialetais (Minas Gerais e Paraíba) podem ou não influenciar no processamento correferencial destas estruturas.

\section{BREVE REVISÃO DA LITERATURA}

O comportamento referencial de elementos pronominais tem sido amplamente discutido na Teoria Linguística. As principais abordagens teóricas, que foram formuladas tentando explicar como se estabelece

\footnotetext{
${ }_{1}^{1}$ Neste trabalho, o pronome se será denominado anáfora. Anáfora, em seu sentido restrito, que só pode ser, segundo a Teoria da Ligação (CHOMSKY, 1981), reflexivos ou recíprocos e devem ser vinculados ao seu antecedente no seu domínio local.
} 
as relações entre pronomes/anáforas com seus antecedentes potenciais são, respectivamente, a Teoria da Ligação (CHOMSKY, 1981) e a Reflexividade (REINHARD; REULAND, 1993).

Na teoria de Princípios e Parâmetros, a subteoria responsável pelas restrições sintáticas à anáfora intrassentencial é a Teoria da Ligação ${ }^{2}$ (Binding Theory, CHOMSKY 1981, 1986). Os princípios por ela governados estabelecem os limites de expressões anafóricas com relações à indexação entre expressões nominais,. O princípio A, que define restrições na referência de anáfora, como reflexivos e recíprocos, prediz que as anáforas devem ser ligadas localmente. Os pronomes, segundo o Princípio B, devem estar livres em seu domínio de regência. E finalmente, as expressões referenciais (ou expressões $\mathrm{R}$ ) devem estar livres em todos os domínios - advoga o Princípio $\mathrm{C}^{3}$.

Portanto, de acordo com o Princípio A, uma sentença contendo uma anáfora é gramatical se possuir um antecedente dentro de seu domínio sintático ${ }^{4}$, por exemplo, dentro da oração que o contém, como em (6a).

(6a) [Paula disse que $\left[\right.$ Joana $_{i}$ machucou-se $e_{i}$ com a agulha. $\left.]\right]$

O antecedente disponível para a anáfora se só pode ser, segundo a BT, Joana. Se a anáfora não possui um antecedente dentro de seu domínio local, a sentença é considerada agramatical, como em (6b). Paula não é um antecedente disponível para se, tornando-se inacessível de se realizar a ligação.

(6b) $*\left[\right.$ Paula $_{i}$ disse que $\left[\right.$ Joana machucou-se $e_{i}$ com a agulha. $\left.]\right]$

A ligação é definida da seguinte forma (CHOMSKY,1981):

(7) Ligação:

A se liga B se e somente se

(i) A c-comande B;

(ii) A e B são coindexados.

Para A e B serem coindexados, B deve se referir a A, ou indicar igual elemento. Em (6a), Joana e se (com sentido de a si mesma) são coindexados uma vez que Joana c-comanda a anáfora se. A restrição estabelecida por c-comando é assim definida:

(8) $\mathrm{C}$ - comando

O nó A c-comanda o nó B se e somente se

(i) A não domina $\mathrm{B}$ e B não domina $\mathrm{A}$;

(ii) o primeiro nó de ramificação dominando A também domina B.

A anáfora se deve ser c-comandada pelo antecedente Joana, isto é, ambos não se dominam uns aos outros e todos os nós que dominam o antecedente Joana também dominam a anáfora, como se pode observar em (8). As anáforas incluem os reflexivos, os recíprocos e os vestígios de DP (sintagma determinante).

De acordo com a BT, a ligação de anáforas (por exemplo, se) e pronomes (por exemplo, ele) está em distribuição complementar, ou seja, um elemento pode ser encontrado somente em um ambiente particular e o outro elemento pode ser encontrado somente no ambiente oposto. Portanto, para o Princípio B, uma sentença seria gramatical se o pronome não possuir um antecedente dentro da mesma oração que o contém, como em (9a); caso contrário, a sentença torna-se agramatical, como em (9b).

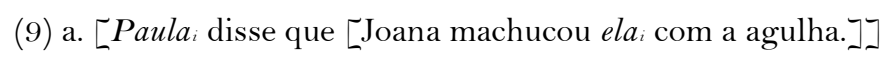

\footnotetext{
${ }^{2}$ Utilizar-se-á, a partir deste ponto, a sigla BT (Binding Theory)

${ }^{s}$ Binding Principles (CHOMSKY, 1986)

A. An anaphor must be A-bound in its binding domain

B. A pronominal must be A-free in its binding domain.

C. An R-expression must be A-free.

${ }^{4}$ De acordo com a notação usual, dois DPs têm a mesma interpretação se possuem o mesmo 'índice'. Nos exemplos apresentados, (6a), (6b), os DPs com mesmo índice foram marcados para facilitar a interpretação.
} 
b.* [Paula disse que [Joana $i$ machucou ela $i$ com a agulha. $]]$

A distribuição complementar entre o Princípio A e o Princípio B prediz que quando uma forma reflexiva pode ser ligada, uma forma pronominal na mesma posição tem de ser livre. No entanto, vários autores têm demonstrado que esta restrição nem sempre se verifica (ESTRELA, 2006). Por exemplo, o Princípio B estabelece que (9)b é agramatical se o pronome ela for interpretado como correferente a Joana, uma vez que, nesse caso, poderia ter sido usado a anáfora se ou a expressão anafórica a si mesma para retomar Joana. $\mathrm{O}$ pronome ela, segundo a teoria da ligação, só pode ser correferente com um antecedente fora do seu domínio local.

Posteriormente, surgem abordagens baseadas na predicação que definem o domínio de ligação das anáforas a partir do predicado e seus argumentos (POLLARD; SAG, 1992; REINHART; REULAND, 1993). Com o objetivo de fazer uma reinterpretação das condições A e B da BT (CHOMSKY, 1981; 1986), Reinhart e Reuland (1993) elaboraram duas teorias independentes: a Teoria da Reflexividade (Binding) dos predicados e a Teoria de Cadeia.

Primeiramente os autores classificam os vários tipos de expressões anafóricas lexicais:

(10) a) os pronomes, que são projetados como DPs;

b) as anáforas, que se dividem em:

(i) anáforas de longa distância, anáforas SE ou anáforas pronominais são orientadas para o sujeito; e são subespecificadas a partir de traços $\varphi$ (pessoa, número e gênero);

(ii) anáforas locais, anáforas SELF, ocupam a posição de núcleo.

Estruturalmente idênticos aos pronomes, as anáforas SE diferem dos pronomes pela falta de uma especificação completa de $\varphi$-features (gênero, número, pessoa); apresentando, principalmente, ausência de traço de número e gênero. Assim sendo, elas não projetam um argumento que pode ser interpretado independentemente, propriedade esta responsável por sua natureza anafórica. Entretanto, a anáfora SELF é um $\mathrm{N}$, em vez de um determinante,e combina-se com um determinante pronome ou um determinante SE.

As expressões lexicais, em relação à referencialidade e reflexivização, são assim classificadas:

Tabela 1 - Quadro proposto sobre reflexividade

\begin{tabular}{l|l|l|l|}
\cline { 2 - 4 } & Anáforas SELF & Anáforas SE & Pronome \\
\hline Reflexividade & + & - & - \\
\hline Independência referencial & - & - & + \\
\hline
\end{tabular}

Segundo a teoria da Reflexivização, (i) um predicado é reflexivo se dois dos seus argumentos estão coindexados; (ii) um predicado $\mathrm{P}$ é reflexivamente marcado se ou $\mathrm{P}$ é reflexivo lexicalmente ou um dos argumentos de P é uma anáfora SELF; e (iii) uma anáfora SELF é uma anáfora complexa que consiste num pronome e num morfema SELF. ${ }^{5}$

O principal preceito desta proposta seria, então, que uma condição não-estrutural pode desempenhar um importante papel sobre predicados na resolução da anáfora. Segundo os autores, haveria dois módulos diferentes de gramática que regulariam a distribuição das diferentes expressões anafóricas - Binding (reflexividade) e Condição de Cadeia.

As restrições de Binding, como apresentadas, não são condições estruturais e apontam sobre a predicação que envolve tanto questões sintáticas quanto semânticas sobre os diversos tipos de expressões anafóricas. As condições referentes ao predicado são assim definidas (REINHART; REULAND, 1993):

(11) Condição A: Um predicado marcado reflexivo deve ser reflexivo.

\footnotetext{
${ }^{5}$ Anáfora SELF funcionaria como um reflexivizador. Esta função é realizada pelo N-SELF. Seria uma espécie de operador que transforma um predicado transitivo em um intransitivo. Contrariamente, a anáfora SE falharia nessa função.
} 
Condição B: Um predicado reflexivo deve ser reflexivo marcado.

Um predicado pode ser reflexivo ou inerente quando um significado reflexivo é especificado no léxico, ou quando dois dos seus argumentos são coindexados na sintaxe. Um predicado pode ser reflexivo-marcado de duas maneiras também: ou inerentemente no léxico ou por ter um reflexivo como himself como seu argumento na sintaxe.

A Condição da Cadeia de Reinhart e Reuland (1993) requer que, em uma cadeia-A, a posição mais alta da cadeia seja ocupada por um elemento totalmente especificado para traços- $\varphi$ e para Caso estrutural; as demais posições (as posições coindexadas com o antecedente) serão subespecificadas ou para traços- $\varphi$, ou para Caso estrutural. Portanto, os pronomes não poderiam ser coindexados porque, por hipótese, seriam completamente especificados para os traços mais relevantes e violariam esta condição.

Baseada na teoria de reflexividade de Reinhart e Reuland (1993) e nos apontamentos de Déchaine e Wiltschko (2002 apud BRITO (2011a; 2011b; 2012)), Brito (2011a) procura explicar as propriedades referenciais da anáfora se do Português Brasileiro. Segundo a autora, a anáfora seria um elemento self, portanto seria + reflexiva e com - independência referencial. Para que o se reflexivo no português brasileiro se estabeleça como um elemento self, a autora sugere, então, a existência de um traço [SELF], presente no se reflexivo. O traço é assim definido:

(12) [SELF] - traço semântico cuja presença atribui ao item que o contém a propriedade de reflexivizador.

Assim, pela proposta de Brito (2011b), a propriedade reflexivizadora do se se dá pela presença do traço [SELF $]$ na sua estrutura interna, sendo este traço semântico responsável pela interpretação reflexiva do predicado em LF (forma lógica).

A partir deste pequeno panorama das restrições das anáforas e pronomes pode-se perceber o quanto diversos fatores podem entrar em jogo na resolução de uma referência anafórica. Assim como as condições de localidade, c-comando, reflexividade de predicados, morfema SELF, entre outros itens, os procedimentos interpretativos e o armazenamento discursivo mostram-se importantes dentro do sistema computacional.

Buscando compreender melhor como ocorre o processamento da linguagem, os estudos psicolinguísticos sobre as restrições de ligação da BT vêm apontando que o processamento correferencial ocorreria em dois estágios. No primeiro estágio, denominado bonding, o parser identificaria e selecionaria os possíveis antecedentes para a resolução correferencial, e no segundo estágio - resolution - realizaria a ligação entre a anáfora e um antecedente potencial (GARROD; SANFORD, 1994).

Um dos primeiros estudos que buscou verificar em que estágio do processamento as restrições de ligação ocorreriam foi relatado por Nicol e Swinney (1989). A partir da técnica de priming inter-modal (ou crossmodal), os estímulos apresentados no priming e no alvo são de modalidades diferentes. Especificamente, neste estudo, os participantes ouviam sentenças e ao mesmo tempo deveriam realizar uma tarefa de decisão lexical a partir de uma palavra sonda (visualizada) que foi apresentada após o pronome (13) e a anáfora (14). Esta palavra sonda poderia ter relação com o boxeador, nadador ou médico.

(13) The boxer told the skier $_{\mathrm{i}}$ that the doctor for the team would blame him *for the recent injury. ${ }^{6}$

(14) The boxer $_{\mathrm{j}}$ told the skier ${ }_{\mathrm{j}}$ that the doctor ${ }_{\mathrm{i}}$ for the team would blame himself $*$ for the recent injury.

Foi observado efeito de priming somente para os antecedentes acessíveis ao pronome him (the boxer e the skier) e a anáfora himself (the doctor), mas não foi encontrado efeito em relação aos antecedentes indisponíveis. Estes não foram levados em consideração durante a resolução da correferência. Os resultados sugerem que somente os antecedentes disponíveis estruturalmente influenciariam a resolução da correferência, e formulam, então, a Hipótese de Filtro Inicial. Segundo esta hipótese, as restrições sintáticas da BT atuariam no início do processamento, ou seja, em bonding, ativando os antecedentes possíveis para a

${ }^{6} \mathrm{O}$ boxeador falou para o esquiador que o médico da equipe culpa ele da recente lesão.

O boxeador falou para o esquiador que o médico da equipe culpa ele mesmo da recente lesão. 
resolução da correferência e no estágio subsequente, resolution, concluindo a ligação do sintagma ao antecedente restringido na etapa anterior.

Contrariamente, estudos posteriores apontam que tanto os antecedentes indisponíveis estruturalmente, quanto os disponíveis, influenciam a resolução da correferência, apresentando evidências contra o Filtro de Ligação Inicial (BADECKER; STRAUB, 2002; STURT, 2003; KENNISON, 2003; LEITÃO; PEIXOTO; SANTOS, 2008).

Badecker e Straub (2002), em um experimento de leitura automonitorada (self-paced reading) no qual se manipulou o gênero de antecedentes disponíveis e de antecedentes indisponíveis, encontraram evidências contra esse modelo (Filtro Inicial). Os resultados do experimento, que continham frases como as exemplificadas a seguir, mostraram que os antecedentes indisponíveis influenciaram no tempo de leitura das sentenças.

(15) Pronome ${ }^{7}$

a) John thought that Beth owed him another opportunity to solve the problem.

b) John thought that Bill owed him another opportunity to solve the problem.

(16) Reflexivos ${ }^{8}$

a) Jane thought that Bill owed himself another opportunity to solve the problem.

b) John thought that Bill owed himself another opportunity to solve the problem.

Segundo os autores, as restrições de ligação atuam em paralelo com outros tipos de informações disponíveis (traços de gênero e número, foco discursivo) desde as primeiras fases de processamento, e que elas competem entre si para determinar o resultado da resolução de correferência. Ambos os antecedentes, sejam os acessíveis (disponíveis) ou inacessíveis (indisponíveis) estruturalmente, poderiam influenciar o processamento desde que houvesse um traço, por exemplo, de gênero, que fosse congruente entre retomada e antecedente.

Na mesma perspectiva de Badecker e Straub (2002), Sturt (2003) manipulou o gênero de antecedentes disponíveis e indisponíveis com a retomada anafórica (reflexivos himself e herself) em contextos em que o antecedente indisponível foi colocado como tópico do discurso (Jonathan/Jennifer), utilizando dois experimentos a partir da técnica de rastreamento ocular (eye-tracking) ${ }^{9}$ e outro experimento a partir da leitura automonitorada para verificar como os sujeitos interpretaram a retomada anafórica. Em (17) são reportados o conjunto experimental do experimento 1.

$(17)^{10}$

a) Antecedente disponível - combina (match)/ antecedente indisponível - combina (match)

Jonathan was pretty worried at the City Hospital. He remembered that the surgeon had pricked himself with a used syringe needle. There should be an investigation soon.

${ }^{7}$ a) John pensou que Beth lhe devia mais uma oportunidade para resolver o problema.

b) John pensou que Bill lhe devia mais uma oportunidade para resolver o problema.

${ }^{8}$ a)Jane pensou que Bill devia a ele mesmo mais uma oportunidade para resolver o problema.

b) John pensou que Bill devia a ele mesmo mais uma oportunidade para resolver o problema.

9 O rastreamento ocular é uma técnica de registro (em milésimos de segundo) que captura os movimentos dos olhos, entre eles os dois principais: as fixações e as sacadas. É através da investigação dos tempos de fixação e do número de sacadas para avaliar os custos de processamento das diferentes estruturas das línguas naturais humanas.

10 a) Jonathan estava muito preocupado no Hospital da Cidade. Ele lembrou que o cirurgião tinha picado ele mesmo com uma agulha de seringa usada. Deveria haver uma investigação em breve.

b) Jennifer estava muito preocupada no Hospital da Cidade. Ela lembrou que o cirurgião tinha picado ele mesmo com uma agulha de seringa usada. Deveria haver uma investigação em breve.

c) Jonathan estava muito preocupado no Hospital da Cidade. Ele lembrou que o cirurgião tinha picado ela mesma com uma agulha de seringa usada. Deveria haver uma investigação em breve.

d) Jennifer estava muito preocupada no Hospital da Cidade. Ela lembrou que o cirurgião tinha picado ela mesma com uma agulha de seringa usada. Deveria haver uma investigação em breve. 
b) Antecedente disponível - combina (match)/ antecedente indisponível - não combina (mismatch)

Jennifer was pretty worried at the City Hospital. She remembered that the surgeon had pricked himself with a used syringe needle. There should be an investigation soon.

c) Antecedente disponível- não combina (mismatch)/ antecedente indisponível - combina (match)

Jonathan was pretty worried at the City Hospital. He remembered that the surgeon had pricked herself with a used syringe needle. There should be an investigation soon.

d) Antecedente disponível - não combina (mismatch)/ antecedente indisponível - não combina (mismatch)

Jennifer was pretty worried at the City Hospital. She remembered that the surgeon had pricked herself with a used syringe needle. There should be an investigation soon.

O autor observou que a resolução da correferência de anáforas ocorre em dois estágios de processamento: com antecedentes disponíveis sintaticamente sendo ligados às anáforas, guiados pela Teoria da Ligação $\left(1^{\circ}\right.$ estágio - bonding), e em seguida a partir da influência de antecedentes indisponíveis controlados por aspectos semântico-discursivos ( $2^{\circ}$ estágio - resolution).

A partir das restrições do princípio B, Kennison (2003) analisou a partir da técnica de leitura automonitorada (self-paced reading), os pronomes him, his e her. Para tanto, realizou três experimentos e, assim como Sturt (2003), também capturou dois estágios de processamento.

$(18)^{11}$

Condições SPEC

Susan / watched /her /classmate /during / the open rehearsals / of the /school play.

Carl / watched / her /classmate /during / the open rehearsals / of the /school play.

They / watched /her /classmate /during / the open rehearsals / of the /school play.

Condições NP

Susan /watched /her /yesterday /during / the open rehearsals / of the /school play.

Carl /watched /her /yesterday / during / the open rehearsals / of the /school play.

They /watched /her /yesterday /during/the open rehearsals /of the /school play.

Segundo a pesquisa realizada, a autora sugere que o conjunto inicial de candidatos a antecedentes gerados durante a resolução da correferência contém tanto antecedentes estruturalmente disponíveis quanto os antecedentes indisponíveis, de acordo com os princípios da Teoria da Ligação (CHOMSKY, 1981), diferentemente do que foi proposto por Nicol e Swinney (1989) quando argumentam que somente os antecedentes estruturalmente disponíveis são considerados como antecedentes durante a resolução de correferência (Modelo de Filtro Inicial). Os resultados encontrados dialogam com os estudos Badecker e Straub (2002) e Sturt (2003) sobre a influência de antecedentes indisponíveis. Para Kennison, no processamento da correferência, primeiramente, todos os antecedentes são selecionados. Bonding ocorreria quando é realizada uma ligação (link) entre o pronome ou anáfora e um ou mais candidatos a antecedentes (estruturalmente disponíveis ou não). As restrições de Ligação guiariam os links. No estágio de resolution, aconteceria a avaliação do link criado durante a fase de bonding para então ocorrer à integração do link na interpretação semântica da sentença. Acrescenta-se, ainda, que a resolution pode também envolver a recomputação (re-computation) de ligações, caso seja necessário, podem ocorrer violações dos princípios. A

\footnotetext{
11 Condições SPEC

Susan assistiu o colega de classe dela durante os ensaios abertos ao público da peça escolar.

Carl assistiu o colega de classe dela durante os ensaios abertos ao público da peça escolar.

Eles assistiram o colega de classe dela durante os ensaios abertos ao público da peça escolar.

Condições NP

Susan assistiu ela ontem durante os ensaios abertos ao público da peça escolar.

Carl assistiu ela ontem durante os ensaios abertos ao público da peça escolar.

Eles assistiram ela ontem durante os ensaios abertos ao público da peça escolar.
} 
recomputação ocorreria na fase de decisão, quando um link não é encontrado por um pronome ou anáfora ou quando nenhum dos links disponíveis não consegue atender a um limiar de aceitabilidade para ser integrados com sucesso na interpretação semântica da sentença. Nestas circunstâncias, o leitor continua o processamento relacionando o pronome ou anáfora a uma entidade não mencionada ou mantém as múltiplas interpretações possíveis até que mais tarde selecione um dos links em detrimento de os outros, podendo, assim ligar o pronome ou anáfora a um antecedente estruturalmente indisponível, violando as restrições de ligação. Salienta-se ainda que a fase de decisão seria uma fase separada, com a função de parar o processo pela busca de um antecedente.

Em Português Brasileiro, a partir da técnica de leitura automonitorada, a pesquisa de Leitão, Peixoto e Santos (2008) apresenta resultados semelhantes aos encontrados no inglês (KENNISSON, 2003). Os candidatos a antecedentes indisponíveis foram considerados na resolução da correferência quando combinados em gênero, número e animacidade com o pronome se não houvesse antecedentes disponíveis no escopo discursivo. Havendo um antecedente disponível, a ligação entre pronome e antecedente é estabelecida imediatamente; caso contrário, a ligação será mais lenta ao haver antecedentes indisponíveis que combinam com o pronome anafórico.

$$
\begin{aligned}
& \text { (19) } \\
& \text { a- Antecedente sujeito masculino, singular e + animado (MS+A) } \\
& \text { Tião/ atropelou/ ele/ imprudentemente/ na estrada/de Cabedelo. } \\
& \text { b - Antecedente sujeito feminino, singular e + animado (FS+A) } \\
& \text { Talita/ atropelou/ ele/ imprudentemente/ na estrada/de Cabedelo. } \\
& \text { c - Antecedente sujeito feminino, plural e + animado (FP+A) } \\
& \text { As motoristas/atropelaram/ ele/ imprudentemente/na estrada/de Cabedelo. } \\
& \text { d - Antecedente sujeito feminino, plural e - animado (FP-A) } \\
& \text { As carretas/atropelaram/ ele/ imprudentemente/ na estrada/de Cabedelo. }
\end{aligned}
$$

Também em Português Brasileiro, Oliveira, Leitão e Henrique (2012) realizaram um experimento utilizando a técnica experimental de leitura automonitorada a fim de verificar o tempo de leitura da expressão anafórica a si mesmo(a) em estruturas em que a anáfora é precedida por antecedente disponível e indisponível, segundo a Teoria da Ligação (CHOMSKY, 1981, 1986).

a) Antecedente indisponível feminino, disponível masculino e retomada masculino

FMRM Maria disse que João machucou a si mesmo no parque de diversão. João se machucou?

b) Antecedente indisponível masculino, disponível feminino e retomada masculino

MFRM João disse que Maria machucou a si mesmo no parque de diversão. João se machucou?

c) Antecedente indisponível feminino, disponível masculino e retomada feminino

FMRF Maria disse que João machucou a si mesma no parque de diversão. Maria se machucou?

d) Antecedente indisponível masculino, disponível feminino e retomada feminino

MFRF João disse que Maria machucou a si mesma no parque de diversão. Maria se machucou?

e) Antecedente indisponível masculino, disponível masculino e retomada masculino

MMRM João disse que José machucou a si mesmo no parque de diversão. José se machucou?

f) Antecedente indisponível feminino, disponível feminino e retomada feminino

FFRF Maria disse que Lilian machucou a si mesma no parque de diversão. Lilian se machucou?

Diferentemente, os resultados demonstraram que somente os antecedentes disponíveis estruturalmente foram considerados como antecedentes prováveis a expressão anafórica, corroborando com os achados de Nicol e Swinney (1989) sobre a Hipótese do Filtro Inicial e instigando ainda mais a discussão. 
No que tange os princípios da BT, destacamos, ainda, dois trabalhos a partir de experimentos offline que buscaram analisar o conhecimento linguístico dos aprendizes de língua materna sobre os princípios de ligação. Bertolino e Grolla (2011, 2012) realizaram dois experimentos a partir do método de Tarefa de Julgamento de Valor de Verdade (TJVV) com o objetivo de verificar a aceitabilidade da ligação local do pronome ele, observando o princípio B da BT. No primeiro experimento (GROLLA; BERTOLINO, 2011), a maioria dos participantes, todos adultos, aceitou a leitura do pronome ele sendo vinculado a um antecedente local em estruturas com quantificador $(\mathrm{QP})$ e sem quantificador, quando era um DP.

Como se pode observar na tabela 2, acima, os dados apresentaram $65 \%$ de aceitabilidade do vínculo local do 'ele' a um antecedente DP e 55\% em estruturas QP. As autoras sugerem, então, com base nos resultados que o ele não seria um pronome, mas seria considerado uma UBE (expressão não especificada para ligação). Esta definição é proposta por Zribi-Hertz (1995, apud GROLLA; BERTOLINO, 2011) que, ao pesquisar o 'lui do francês, afirma que a ligação local de uma UBE estaria relacionada à semântica do predicado. As autoras nomeiam os predicados como reflexividade possivel ou improvável e sugerem a inclusão da variável reflexividade improvável num próximo estudo.

Tabela 2 - Sentenças experimentais

\begin{tabular}{|l|l|}
\hline Tipo de sentença & Sentenças \\
\hline Ligação local em matriz (DP) & $\begin{array}{l}\text { O Woody abanou ele. } \\
\text { A Smurfete beijou ela. }\end{array}$ \\
\hline Ligação local em matriz (QP) & $\begin{array}{l}\text { Cada gato cobriu ele. } \\
\text { Cada fantasma enxugou ele. }\end{array}$ \\
\hline Ligação local em elipse de VP (DP) & $\begin{array}{l}\text { A Margarida estava lavando ela e a Joaninha também estava. } \\
\text { A Jasmine estava abanando ela e a Lea também estava. }\end{array}$ \\
\hline Ligação local em elipse de VP (QP) & $\begin{array}{l}\text { O Piteco estava cheirando ele e cada dinossauro também estava. } \\
\text { O Fred estava coçando ele e cada hipopótamo também estava. }\end{array}$ \\
\hline
\end{tabular}

Fonte: Grolla e Bertolino (2011).

Em Bertolino e Grolla (2012), os estímulos de 2011 foram reformulados e aplicados em adultos e crianças. A partir dos resultados encontrados no segundo experimento, concluíram que ele seria um pronome estando sujeito ao princípio B, contrariamente aos resultados encontrados no primeiro experimento.

Tabela 3 - Sentenças experimentais

\begin{tabular}{|c|c|}
\hline Tipo de sentença & Sentenças \\
\hline $\begin{array}{l}\text { Ligação local em predicado [-reflexivo] } \\
\text { (DP) }\end{array}$ & $\begin{array}{l}\text { A Bela brigou com ela. } \\
\text { A Zazá conversou com ela. } \\
\text { O Smurf ciclista brincou com ele. } \\
\text { O Peri salvou ele. }\end{array}$ \\
\hline $\begin{array}{l}\text { Ligação local em predicado [-reflexivo] } \\
\text { (QP) }\end{array}$ & $\begin{array}{l}\text { Cada princesa brigou com ela. } \\
\text { Cada galinha conversou com ela. } \\
\text { Cada Smurf brincou com ele. } \\
\text { Cada índio salvou ele. }\end{array}$ \\
\hline $\begin{array}{l}\text { Ligação local em predicado [+reflexivo] } \\
\text { (DP) }\end{array}$ & $\begin{array}{l}\text { O Oscar molhou ele. } \\
\text { O homem aranha pintou ele. } \\
\text { O Dino coçou ele. } \\
\text { O vovô Bernardo enxugou ele. }\end{array}$ \\
\hline $\begin{array}{l}\text { Ligação local em predicado [+reflexivo] } \\
\text { (QP) }\end{array}$ & $\begin{array}{l}\text { Cada alienígena molhou ele. } \\
\text { Cada super-heroi pintou ele. } \\
\text { Cada dinossauro coçou ele. } \\
\text { Cada vovô enxugou ele. }\end{array}$ \\
\hline
\end{tabular}

Fonte: Bertolino e Grolla (2012).

A maioria dos estudos online supracitados encontrou diferentes sensibilidades (gênero, número, animacidade, localidade) referentes às anáforas ou expressões anafóricas e aos pronomes, focalizando seus estudos em orações justapostas, coordenadas ou relativas que continham antecedentes disponíveis e indisponíveis, segundo a BT (CHOMSKY, 1981; 1986). Se por um lado, alguns desses estudos apontaram que as restrições dos princípios de ligação restringiram a correferência, por outro lado, os resultados de outros estudos demonstram que as restrições não agiriam como filtro absoluto, podendo ser, posteriormente, reanalisadas. A fim de compreender melhor sobre este fenômeno, um dos principais 
objetivos aqui é investigar como os princípios agiriam e se aplicariam no domínio da resolução de referência, ou seja, dentro da cláusula sem manipulação de gênero e número dos antecedentes anafóricos. Diante da diversidade de formas anafóricas presentes do português brasileiro, este trabalho investigará se a variação dialetal poderia influenciar o desempenho de falantes de regiões distintas na leitura de estruturas aqui testadas.

\section{EXPERIMENTO}

O experimento aplicado neste trabalho utilizou a técnica online de leitura automonitorada (self-paced reading) em que os participantes monitoram sua própria leitura em frente à tela do computador, pressionando a tecla $\mathrm{L}$ do teclado, e as teclas $\mathrm{O}$ e $\mathrm{P}$, respectivamente sim ou não, em uma sala isolada.

No experimento foram manipuladas três variáveis independentes: tipo de retomada [reflexiva - se, nula - ø e pronominal - ele (a)], tipo de verbo (verbos prováveis reflexivos e prováveis não reflexivos) e tipo de grupo (Minas Gerais e Paraíba).

Combinando as 3 variáveis independentes em um design 3x2x2 obteve-se seis condições exemplificadas e apresentadas na Tabela 4, assim formando um conjunto experimental.

VRRR (verbo provável reflexivo com retomada reflexiva), VRRN (verbo provável reflexivo com retomada nula), VRRP (verbo provável reflexivo com retomada pronominal) VNRR (verbo provável não reflexivo com retomada reflexiva), VNRN (verbo provável não reflexivo com retomada nula) VNRP (verbo provável não reflexivo com retomada pronominal). A variável dependente online foi o tempo de leitura do segmento crítico e do segmento seguinte.

Tabela 4 - Exemplo de sentenças por condições experimentais

\begin{tabular}{|l|l|}
\hline VVRRR & $\begin{array}{l}\text { Verbo provável reflexivo com retomada reflexiva } \\
\text { Marcelo/machucou se }\end{array}$ 12 no parque de diversão./ Marcelo machucou a si mesmo? \\
\hline VVRRN & $\begin{array}{l}\text { Verbo provável reflexivo com retomada nula (ø) } \\
\text { Marcelo/ machucou na escola de música./ Marcelo machucou a si mesmo? }\end{array}$ \\
\hline VVRRP & $\begin{array}{l}\text { Verbo provável reflexivo com retomada pronominal } \\
\text { Marcelo/ machucou ele no parque de diversão./ Marcelo machucou a si mesmo? }\end{array}$ \\
\hline VVNRR & $\begin{array}{l}\text { Verbo provável não reflexivo com retomada reflexiva } \\
\text { Fabiana/ picou se com a agulha/ de costura./ Fabiana picou a si mesma? }\end{array}$ \\
\hline VVNRN & $\begin{array}{l}\text { Verbo provável não reflexivo com retomada nula (ø) } \\
\text { Fabiana/ picou ø com o alfinete/ de costura. / Fabiana picou a si mesma? }\end{array}$ \\
\hline VVNRP & $\begin{array}{l}\text { Verbo provável não reflexivo com retomada pronominal } \\
\text { Fabiana/ picou ele com a agulha/ de costura./ Fabiana picou a si mesma? }\end{array}$ \\
\hline
\end{tabular}

Após cada sentença experimental houve uma pergunta para verificar como os participantes interpretaram a reflexividade da frase. Este procedimento offline, também de coleta dados, objetivou verificar como as variáveis manipuladas foram consideradas pelos sujeitos que participaram deste experimento.

Espera-se, a partir de uma perspectiva puramente estrutural que a manipulação do verbo não deve afetar a resolução da referência. Entretanto, esperamos que as preferências estruturais da anáfora e do pronome sejam afetadas pela manipulação do verbo corroborando com Reinhart e Reuland (1993), e que a variação dialetal existente no Português Brasileiro na região Sudeste, mais especificamente em Minas Gerais, possa interferir no processamento das estruturas aqui analisadas.

\footnotetext{
${ }^{12} \mathrm{~A}$ anáfora se foi propositalmente coloca na posição de ênclise para que no segmento 2 o leitor tivesse acesso primeiramente ao verbo e para que a retomada anafórica estivesse na mesma posição estrutural em todas as condições experimentais.
} 
Se nas fases iniciais do processamento, tanto os pronomes e os reflexivos forem guiados somente por informações estruturais e houver uma reanálise na interpretação, principalmente do pronome, numa fase posterior do processamento, os experimentos corroborarão com pesquisas como de Sturt (2003). Entretanto, se os dados empíricos demonstrarem que haveria várias restrições agindo simultaneamente, o dialogo se estabelecerá com pesquisas como, por exemplo, Badecker e Straub (2002).

\subsection{Métodos}

\subsubsection{Participantes}

Para a realização desta pesquisa ${ }^{13}$, que envolve questões de variação dialetal, participaram, voluntariamente, 50 sujeitos, ambos alunos de graduação de cursos diversos (dentre eles, Psicologia, Geografia, História, Pedagogia, Letras) de duas Universidades de regiões distintas. O experimento foi aplicado primeiramente com 25 sujeitos, alunos de graduação do INESP/UEMG - Campus 1 Divinópolis/MG - com idade entre 18 a 40 anos, falantes nativos do Português Brasileiro. Posteriormente, o mesmo experimento foi reaplicado na região nordeste do Brasil com a participação voluntária de 25 sujeitos, alunos de graduação da UFPB - Campus 1 João Pessoa - com idade entre 20 a 40 anos, falantes nativos do Português Brasileiro.

\subsubsection{Material}

O material consistiu de três conjuntos de 15 frases experimentais, sendo 8 com verbos prováveis reflexivos e 7 com verbos prováveis não reflexivos. Os estímulos foram organizados a partir do desenho do quadrado latino em três listas, ou seja, distribuição intrassujeitos.

Os verbos utilizados foram selecionados a partir dos estímulos do experimento de leitura automonitorada de Oliveira et al (2012). Os verbos considerados aqui como reflexivos são aqueles que o argumento executa a ação em si, em termos de funções temáticas, sendo simultaneamente o agente e o tema da ação descrita pelo verbo. Entretanto, os verbos reflexivos foram subdivididos em dois grupos ${ }^{14}$. O primeiro grupo com verbos prováveis reflexivos, ou seja, verbos mais marcados reflexivamente; e o segundo grupo com verbos prováveis não reflexivos, verbos menos marcado reflexivamente.

Cada informante foi exposto a um desses conjuntos experimentais, associados a um conjunto extra de 30 frases distratoras, totalizando assim 45 frases.

O aparato experimental, para a aplicação do experimento, consistiu de um Macbook Pro 15 (2,4 GHz) em conjunto com o programa Psyscope (COHEN, J. D.; MACWHINNEY, B.; FLATT, M.; PROVOST, S., 1993).

\subsubsection{Procedimentos}

O experimento, elaborado por meio do programa Psyscope, utilizou a técnica online de leitura automonitorada (self-paced reading) em que os participantes monitoram sua própria leitura em frente à tela do computador e ao teclado, em uma sala isolada (cedida pela instituição). A tarefa consistiu em ler, em velocidade natural, sentenças divididas em 3 segmentos, como pudemos observar na lista de condições experimentais já mencionada (VRRR; VRRN; VRRP; VNRR; VNRN; VNRP). Os participantes foram testados individualmente e todos foram, primeiramente, orientados oralmente pelo experimentador e depois por instruções que apareceram na tela do computador. Todos realizaram um teste de prática, com o objetivo de verificar se os mesmos tinham compreendido a tarefa a ser realizada e solucionar possíveis dúvidas com o procedimento experimental. O início da tarefa consistiu em ler o primeiro segmento e, ao apertar a letra L do teclado a sua frente, o participante fez com que esse segmento sumisse. Automaticamente, o segundo segmento apareceu e assim procedeu até o último segmento (final da frase), sinalizado com um ponto final. Logo em seguida, apareceu uma pergunta a respeito da sentença lida e o participante teve que responder

\footnotetext{
${ }^{13}$ Este estudo aprovado sob o número CAAE 11764113.2.0000.518768

${ }^{14}$ Com base em Bertolino e Grolla (2012) dividimos os verbos utilizados neste trabalho em prováveis e não prováveis reflexivos. Esta divisão foi feita com base na intuição de falantes nativos do português, sendo assim, precisamos fazer um estudo mais aprofundado em relação a essa categorização.
} 
apertando a tecla SIM ou a tecla NÃO. Com essa pergunta, objetivamos controlar a atenção e verificar como os sujeitos interpretaram as sentenças.

\subsubsection{Resultados e Discussão}

Os resultados do experimento, expressos nos gráficos 1 e 2 , mostram os tempos médios de leitura na região crítica e na região posterior a retomada. Os dados analisados foram submetidos à análise de variância (Anova, teste T). Houve efeito significativo no segmento crítico e pós-crítico.

Gráfico 1 - Distribuição das médias dos tempos de leitura do segmento crítico e pós critico por condição experimental observando o tipo de verbo - Grupo Minas Gerais

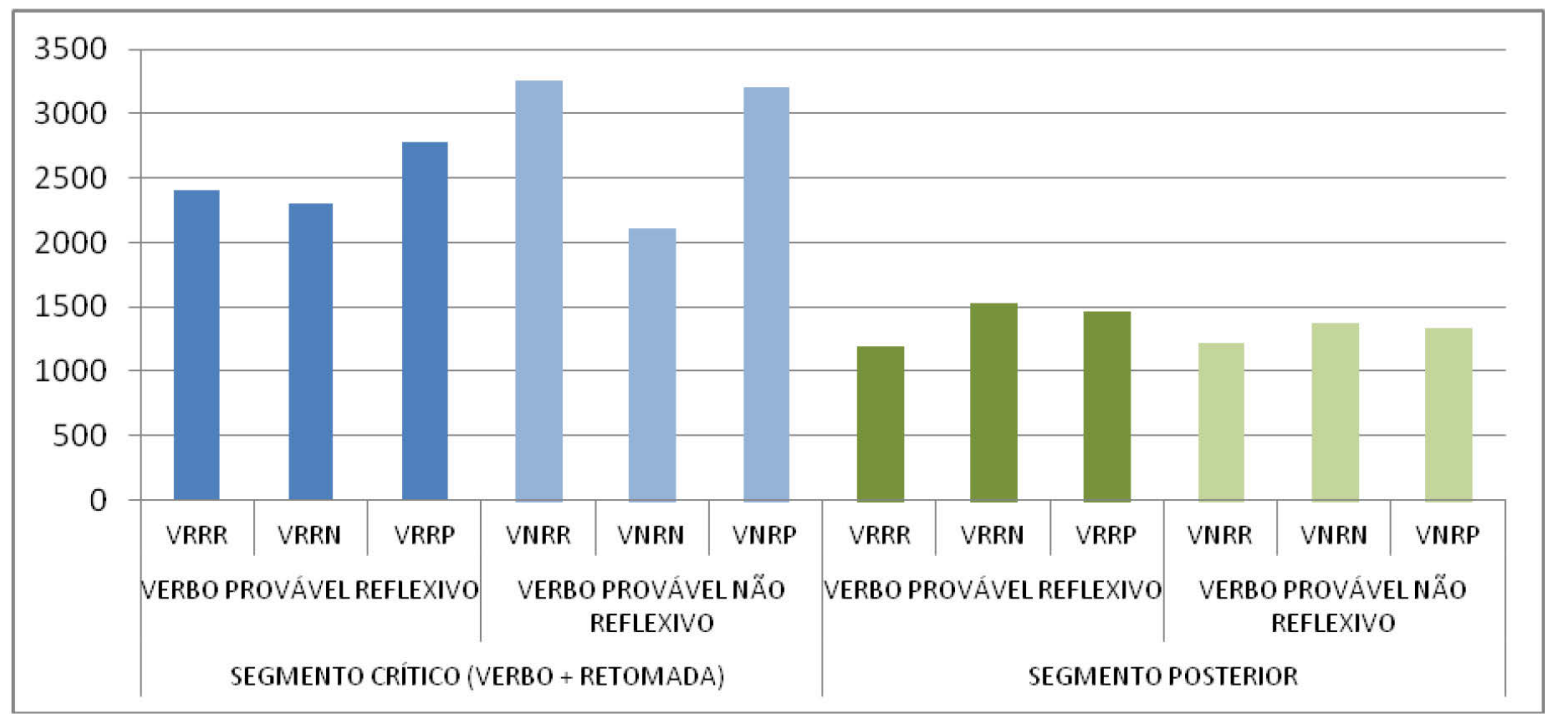

No segmento crítico, não houve um efeito principal de tipo de retomada $(\mathrm{F}(2,119)=2,54 \mathrm{p}=0,08)$. Houve efeito principal de verbo $(\mathrm{F}(2,119)=204,76 \mathrm{p}<0,0001)$ e interação entre anáfora vs verbo $(\mathrm{F}(2,119)=9,80$ $\mathrm{p}<0,0001)$. As sub-análises realizadas utilizando o Teste-t pareado revelaram efeitos significativos entre as condições VRRN e VRRP $(t(24)=-2,86 \mathrm{p}<0.01$, VNRR e VNRN $(t(24)=5,14 \mathrm{p}<0.001), \operatorname{VNRN}$ e $\operatorname{VNRP}(t$ $(24)=-3,59, \mathrm{p}=0.001)$, VRRR e $\operatorname{VNRR}(t(24)=-5,01 \mathrm{p}<0.001)$.

Nas estruturas com verbos prováveis reflexivos, as condições VRRR e VRRN obtiveram tempos de leitura bastante aproximadas (respectivamente, $2401 \mathrm{~ms}$ e $2301 \mathrm{~ms}$ ), sugerindo que o processamento de estruturas com a anáfora se ou nula (ø) são quase que isomórficas, não havendo por parte do leitor nenhum estranhamento quanto à ausência anafórica. Os resultados vão ao encontro inicialmente previsto, partindo do pressuposto que em Minas Gerais existe a possibilidade de uso de estruturas com a presença ou supressão da anáfora se (D’ALBUQUERQUE, 1984; CAMACHO, 2003; MELO, 2005; RIBEIRO, 2010; CARVALHO, 2008; OLIVEIRA, 2006). Na condição com a retomada pronominal, VRRP, houve um maior custo de processamento. Segundo a Teoria da Ligação, o princípio B restringe a correferência do ele ao antecedente intrassentencial, e por não haver um antecedente disponível elucidado na estrutura frasal o tempo de leitura foi maior.

Entretanto, em predicados menos marcados reflexivamente (VN), a presença da anáfora se em contraste com uma predicação menos marcada, neste contexto, causou um aumento no tempo de leitura. A computação sintática/semântica entre o verbo e anáfora, supostamente, tornou o predicado mais reflexivo.

No segmento pós-crítico, houve efeito principal de tipo de retomada nas condições com predicado mais reflexivo $(\mathrm{F}(5,119)=3,97 \mathrm{p}<0,05)$. Não houve efeito principal de tipo de verbo $(\mathrm{F}(5,119)=1,31 \mathrm{p}=0,25) \mathrm{e}$ interação entre tipo de retomada e tipo de $\operatorname{verbo}(\mathrm{F}(5,119)=0,55 \mathrm{p}=0,5)$. As sub-análises realizadas utilizando o Teste- $t$ pareado revelaram efeitos significativos entre as condições VRRR e VRRN $(t(24)=-3,07$ $\mathrm{p}<0.01)$ e VRRR e VRRP $(t(24)=-2,70 \mathrm{p}<0.01)$. Em predicados menos marcados reflexivamente $(\mathrm{VN})$ não houve efeito principal. 
Após a análise do segmento seguinte, os dados parecem apontar a influência do tipo de predicado (REINHART; REULAND, 1993). Diante da supressão da anáfora $s$, o predicado permanece reflexivo e a ligação é realizada, isto é, a interpretação da frase resulta de uma abordagem composicional: existe um único argumento fonologicamente não realizado que, em conjugação com a semântica do verbo em questão, induz a leitura reflexiva.

A partir dos dados offline podemos confirmar que a presença da anáfora se marcou a frase como reflexiva, independente do tipo de verbo, corroborando com os apontamentos de Reinhart e Reuland (1993) A anáfora se, assim como SELF, tem a propriedade de marcar um predicado (BRITO, 2012). Na ausência da anáfora reflexiva, a semântica do verbo é quem parece sinalizar a reflexividade do predicado. Quando a anáfora era substituída pelo pronome ele(a), independente do tipo de predicado, houve mais de $50 \%$ de interpretações considerando o pronome como sendo correferente ao argumento externo, sendo localmente ligado. Sugerese, então, que o Princípio B não agiria como um filtro absoluto sobre a interpretação final da referência anafórica (BADECKER; STRAUB, 2002; STURT, 2003). Por não haver um antecedente acessível ao pronome, talvez, a única alternativa foi realizar a ligação, uma vez que isso também ocorre em predicados menos marcados reflexivamente. Os resultados sugerem que estas interpretações, consideradas agramaticais, foram estabelecidas relativamente tarde no processo.

Gráfico 2 - Índice (\%) de aceitabilidade das anáforas em relação às perguntas sobre reflexividade ao final das frases - Grupo Minas Gerais

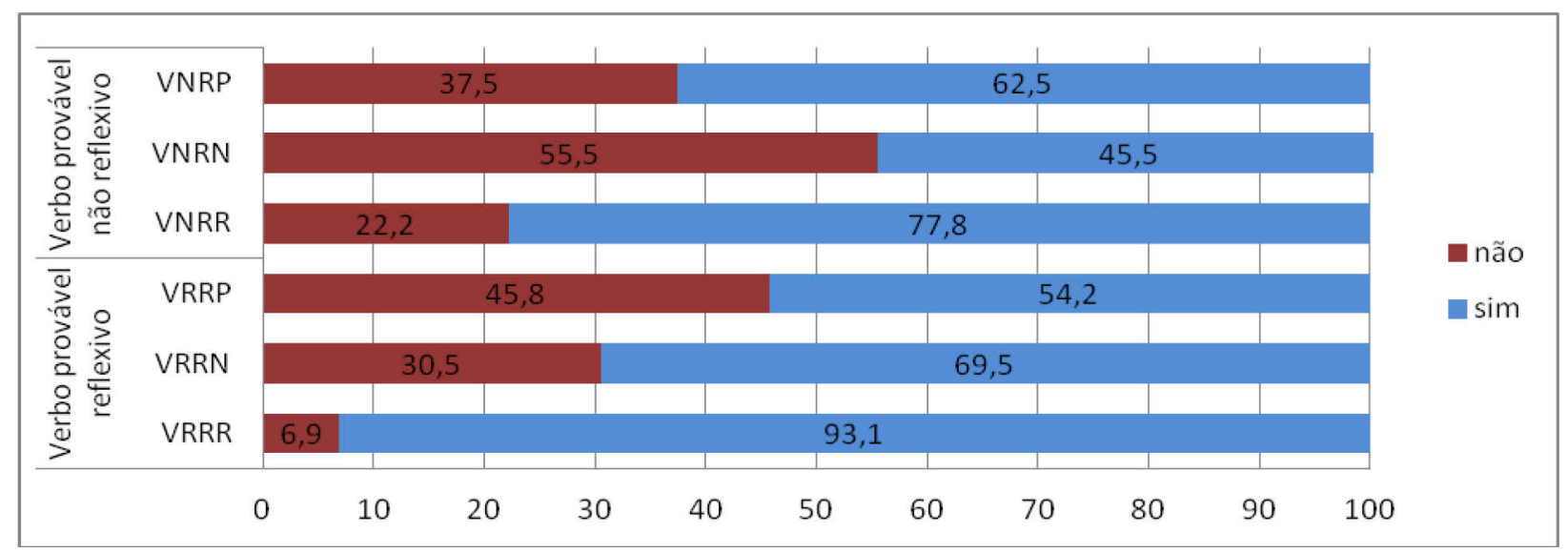

Nota: $\mathrm{RP}=$ Retomada pronominal; $\mathrm{RN}=$ Retomada nula; e RR = Retomada reflexiva.

Observaram-se dados significativamente relevantes em quase todas as condições experimentais, a exceção da condição $\operatorname{VRRP}(p=0,47)$.

Os dados do grupo Paraíba foram analisados a seguir a partir do pacote estatístico $A N O V A$. No gráfico 3 , a análise da variância apresentou efeito principal de tipo de retomada $(\mathrm{F}(5,119)=7.6, \mathrm{p}<0.001)$. Não houve efeito significativo de tipo de verbo $(\mathrm{F}(5,119)=2.24, \mathrm{p}=0.15)$ e nenhuma interação entre anáfora vs verbo $(\mathrm{F}(5,119)=1,91, \mathrm{p}=0.13)$. As sub-análises realizadas utilizando o Teste-t pareado revelaram efeitos significativos entre as condições VRRR e VRRN $(t(24)=2,32 \mathrm{p}<0.05)$, VRRN e VRRP $(t(24)=-3,62$ $\mathrm{p}<0.001, \operatorname{VNRR}$ e VNRN $(t(24)=5,04, \mathrm{p}<0.001)$, VNRN e VNRP $(t(24)=-3,24, \mathrm{p}<0.01), \operatorname{VRRR}$ e VNRR $(t(24)=-3,45 \mathrm{p}<0.01)$.

As condições VRRN e VNRN obtiveram médias do tempo de leitura menores comparadas às demais condições e muito aproximado entre elas (1817 ms e $1890 \mathrm{~ms}$, respectivamente). No momento que o verbo é ativado no léxico, será realizada uma operação lexical para verificação de traços (por exemplo, semânticos, sintáticos) e se obter as informações relacionadas com a estrutura argumental (argumento interno e externo). Por não haver neste segmento o argumento interno, instintivamente, cadencia-se ao próximo segmento para tentar fechar a grade argumental do verbo. Ao avançarem para o próximo segmento, causarão neste um aumento de custo de processamento, por conseguinte, elevando o tempo de leitura.

Contrariamente aos dados de Minas Gerais, os leitores não demonstraram ser influenciados pela semântica do verbo com a retomada nula. Entretanto, a influência no grupo Paraíba também ocorre. Se observarmos 
as médias dos dois tipos de retomada reflexiva notaremos que ocorre um estranhamento entre a semântica do verbo e a presença da anáfora - em VNRR o tempo de leitura se eleva (comparado a VRRR).

As condições com retomada pronominal (RP) tiveram médias de tempo de leitura maiores devido às restrições do Princípio B da BT (CHOMSKY, 1981). Elas predizem que o pronome ele(a) deve estar livre em domínio local ${ }^{15}$, não podendo portanto, ser correferencial ao sujeito da frase. As altas médias, provavelmente, se justificam pela ausência de um antecedente disponível estruturalmente.

Gráfico 3 - Distribuição das médias dos tempos de leitura do segmento crítico e pós critico por condição experimental observando o tipo de verbo - Grupo Paraíba

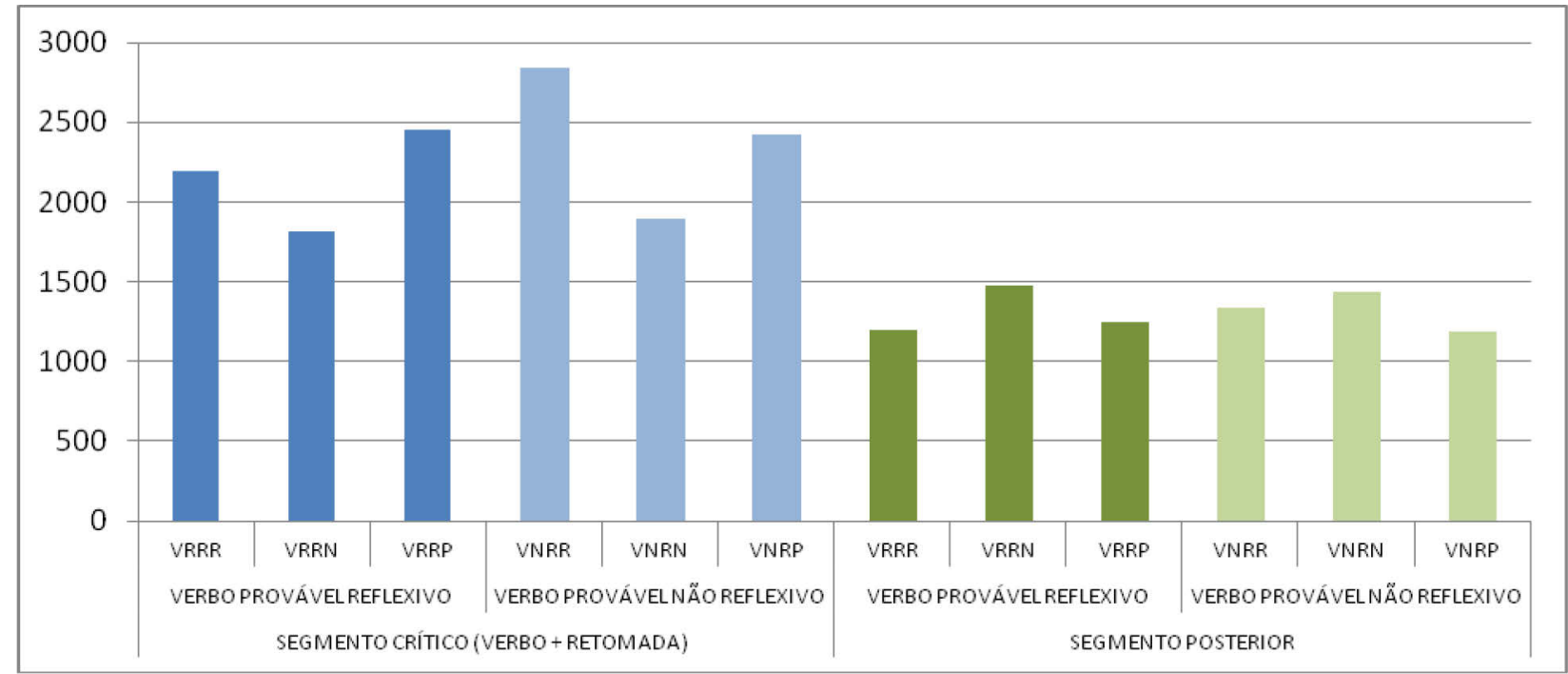

Nota: RP = Retomada pronominal; RN = Retomada nula; e $\mathrm{RR}=$ Retomada reflexiva.

No segmento seguinte ao crítico, a análise de variância apresentou efeito principal de tipo de retomada ( $\mathrm{F}$ $(5,119)=4,82, \mathrm{p}<0.01)$. Não houve efeito significativo de tipo de verbo $(\mathrm{F}(5,119)=1,56, \mathrm{p}=0.21)$ e nenhuma interação entre anáfora $v s$ verbo $(\mathrm{F}(5,119)=0,24, \mathrm{p}=0.78)$. As sub-análises realizadas utilizando o Teste- $t$ pareado revelaram efeito significativo entre as condições VNRR e VNRP $(t(24)=2,50 \mathrm{p}<0.05)$, e efeito marginal entre as condições VRRR e $\operatorname{VRRN}(t(24)=-1,91 \mathrm{p}=0.06$, VRRN e VRRP $(t(24)=-1,81, \mathrm{p}=0.08)$ e VNRR e VNRN $(t(24)=-1,86, \mathrm{p}=0.07)$.

As retomadas nulas $(\mathrm{RN})$ demandaram um maior tempo de processamento, independente do tipo de verbo. $\mathrm{O}$ item lexical ao ser identificado como predicador, esse input projeta seus argumentos, mas neste caso a ausência do argumento interno causa, então, um estranhamento pelo parsing. Nas condições com retomada pronominal (RP), os tempos de leitura de ambas as condições (VRRP e VNRP) foram similares a condição $V R R N$ indicando assim que o analisador considerou o pronome como referente a um antecedente qualquer fora do discurso, não realizando uma ligação local que contrariaria o princípio $B$ da Teoria da Ligação. Esses dados demonstram e fortalecem nossas hipóteses iniciais sobre o pronome estar restringido pelo princípio de Ligação que, diferentemente de Minas Gerais não existem relatos sociolinguísticos ou de outras vertentes sobre o uso de ele (a) como reflexivo.

Para fornecer uma visão geral dos resultados obtidos e, em seguida, verificar se as restrições verificadas se mantiveram na interpretação da sentença - dados- ou se posteriormente houve uma releitura, apresentamse as respostas para as perguntas que se localizavam ao final de cada frase analisada.

Nos dados offline, nas condições com retomada reflexiva (RR), houve uma preferência geral para interpretar a anáfora reflexiva como correferente ao antecedente disponível localmente: em geral, em todos os tipos de verbo havia mais respostas sim com uma pequena diferença quando o predicado era mais marcado (90,2\%) de quando o predicado era mesmo marcado reflexivamente $(86,1 \%)$, portanto as escolhas não foram

${ }^{15}$ Por exemplo, na estrutura “ Marcelo machucou ele no parque de diversão.” segundo o Princípio B da BT ele só pode referir-se o outro antecedente, jamais a Marcelo. 
moduladas pela manipulação do tipo de verbo. Entretanto, assim como em Minas Gerais, a presença da anáfora se marcou a reflexividade conduzindo a interpretação reflexiva.

Gráfico 4 - Índice (\%) de aceitabilidade das anáforas em relação às perguntas sobre reflexividade - Grupo Paraíba
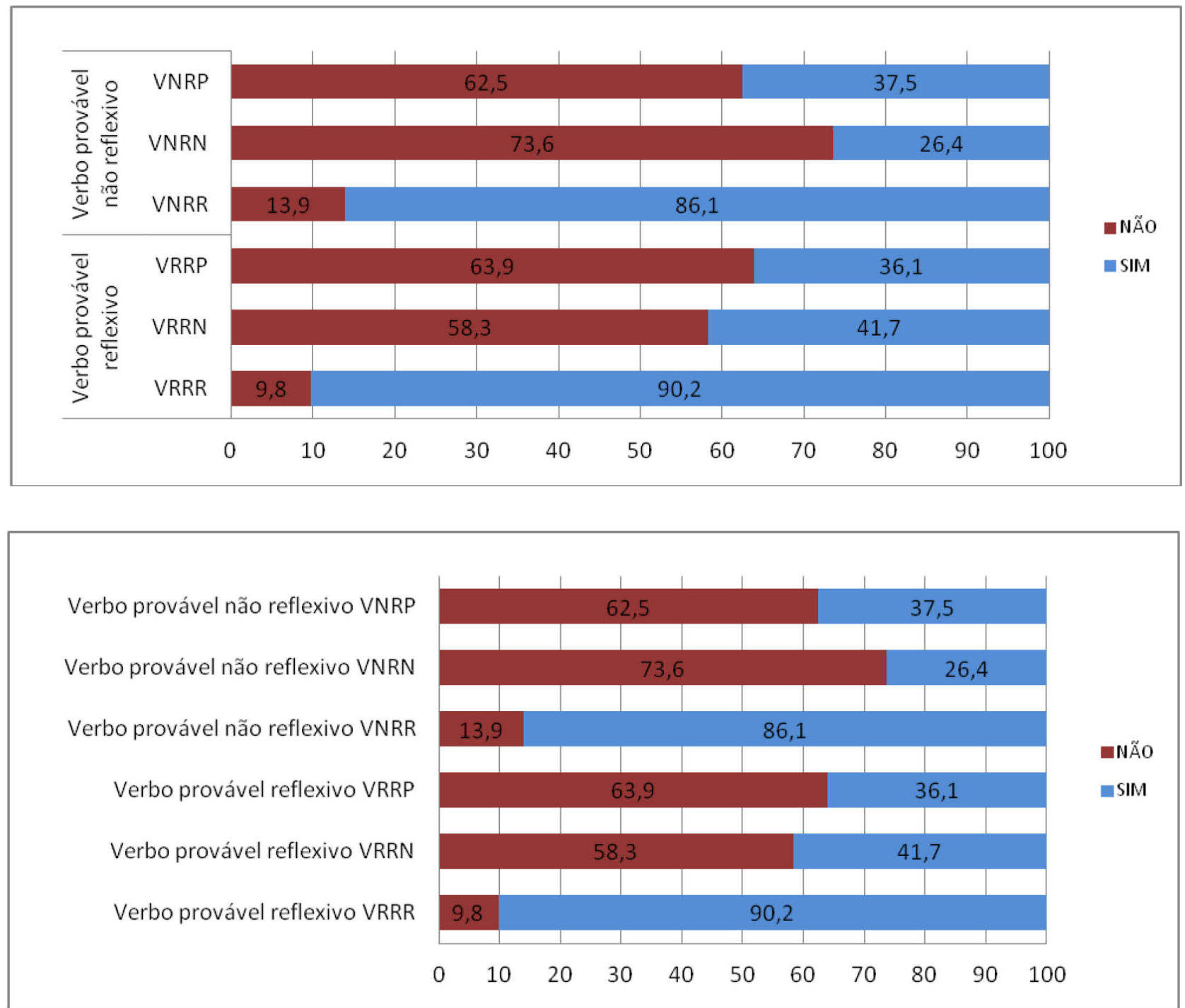

Nota: $\mathrm{RP}=$ Retomada pronominal; $\mathrm{RN}=$ Retomada nula; e $\mathrm{RR}=$ Retomada reflexiva.

As construções com retomadas com o pronome ele(a) foram interpretadas, em sua maioria, como não reflexivas, sendo relacionadas a um antecedente fora do escopo da sentença.

As retomadas nulas (RN), ao contrário de Minas Gerais, não foram analisadas como reflexivas (VNRN $73,6 \%$ e VRRN-58,3\%). A ausência do argumento interno do verbo, somada ao não uso da variável nula em construções reflexivas nesta região (nordeste) adjungiu em respostas negativas, causando a agramaticalidade da sentença.

Os dados empíricos, a partir da técnica de leitura automonitorada, demonstraram que após o acesso lexical, no início do processamento - em bonding, foram selecionados os candidatos a antecedentes. Então, as restrições da BT testariam os links para guiar e ocorrer à ligação. Se algum dos candidatos não atendesse as restrições, poderia ocorrer recomputações - em resolution, influenciando a interpretação semântica da sentença. Vamos advogar, assim como Sturt (2003), que inicialmente as restrições de ligação guiaram o processamento - em bonding, e logo após, sobre a influência da compatibilidade de traços, ocorreu ligação. Os dados da retomada pronominal apontam para essa possibilidade. Houve 58\% de respostas de interpretação considerando a ligação local no grupo Minas Gerais e 37\% no grupo Paraíba. 
A possibilidade do uso do pronome ele, nem que seja como um elsewhere case (MENUZZI, 1997) ${ }^{16}$, sendo ligado a um referente local, talvez, tenha sido fortemente induzido pela variação dialetal em decorrência da possibilidade de alternativas de representações para uma mesma sentença. Assim como Bertolino e Grolla (2012), o pronome ele(a) não é considerado como uma UBE (expressão não especificada para ligação), visto que o Princípio B parece restringir a ligação em bonding. Considera-se que sob a influência de traços convergentes e ausência de antecedentes disponíveis, ocorreu em resolution a recomputação da ligação (KENNISON, 2003). A ligação pode ter sido influenciada também pela saliência do antecedente indisponível como tópico discursivo e, neste caso, haveria uma relação de correferência e não de reflexividade. Acredita-se que tenha sido realizada uma leitura superficial (RIBEIRO, 2008).

A influência da variação dialetal presente nas duas regiões do Brasil é notória nos grupos Minas Gerais e Paraíba. No grupo Minas Gerais, tanto online como offline, apresentou desempenho linguístico confirmando os apontamentos sobre a supressão do se não prejudicar a interpretação reflexiva da frase. Por outro lado, o grupo Paraíba, que apresentava um histórico de dados de corpus oposto ao grupo de Minas Gerais pela duplicação, inserção, e substituição do se reflexivo, também corroborou com os apontamentos de pesquisas com dados de corpus.

Outro ponto importante, ainda relacionado à frequência, diz respeito ao uso dos verbos como reflexivos. Apesar de, nesta pesquisa, este procedimento não ter ocorrido de forma tão criteriosa, os resultados encontrados sugerem uma possível influência do tipo de verbo na resolução da correferência. $\mathrm{O}$ argumento foneticamente nulo só pôde ser interpretado como um elemento anafórico no grupo de Minas Gerais, o qual não é acessado/processado no grupo Paraíba. Para além da ausência de um dos argumentos do predicador, a frequência de uso de um objeto nulo reflexivo tenha sido um fator importante nesta condição, uma vez que, o objeto nulo reflexivo, mais especificamente, não apresenta a mesma frequência de uso em ambas as regiões: é amplamente usado em Minas Gerais e pouco utilizado na Paraíba.

Nas condições com retomada reflexiva $(\mathrm{RR})$, o tipo de verbo em contraste com a presença de anáfora se em predicados menos marcados reflexivamente eleva significativamente os tempos de leitura em ambos os grupos. Este maior custo operacional parece demonstrar que a presença da anáfora torna o predicado reflexivo (REINHART; REULAND, 1993). Reuland (2006) considera que os clíticos reflexivos (francês se, italiano si) não se enquadram na classe de anáfora SE (REINHART; REULAND, 1993), o que também demonstra ocorrer com se do português brasileiro. Uma possibilidade já estabelecida por Brito (2011a, 2011 b 2012) seria que anáfora se seria comparada a uma anáfora do tipo SELF, para isso receberia um traço [SELF] no léxico, que transformaria o predicador em reflexivo na interface sintaxe/semântica na LF. Os resultados encontrados demonstram que anáfora se valora um predicador (transitivo) tornando-o reflexivo (REINHART; REULAND, 1993).

\section{CONSIDERAÇÕES FINAIS}

Por fim, conclui-se que, as restrições dos princípios de ligação foram aplicadas o mais breve possível nas etapas do processamento, mas contrariamente ao que propôs Nicol e Swinney (1989) e Oliveira et al (2012) sobre a influência de, somente os antecedentes disponíveis estruturalmente atuarem na resolução da correferência (NICOL; SWINNEY, 1989). Os dados aqui analisados mostram que ele foi influenciado por um antecedente indisponível, de acordo com o princípio B, corroborando com os achados de Kennison (2003), Sturt (2003), mas sendo também influenciados pela semântica do verbo e pela variação dialetal. Considera-se que as restrições de ligação ocorrem rapidamente no início do processamento- em bonding. Em resolution, agem em paralelo com outros mecanismos interpretativos influenciando o processamento linguístico. Portanto, as restrições sintáticas, associada a informações semânticas e discursivas podem ocorrer no processamento linguístico de sentenças. Entretanto, os parâmetros internos de uma língua a partir de variação dialetal de regiões distintas também devem ser considerados. Caberá, então, ao sistema de interpretação ser capaz de atribuir valores às expressões incluindo uma combinação de processos de recuperação e se baseando na expectativa discursiva particular.

\footnotetext{
${ }^{16}$ Segundo Menuzzi (1997), por estarem em competição entre si, anáforas e pronomes, são escolhidas por um critério de exclusão: primeiramente são verificadas as formas que sofrem mais restrições - no caso as anáforas - e depois as demais. Os pronomes são escolhidos quando os demais “competidores” são descartados. Por tanto, os pronomes são considerados, em geral, como 'elsewhere case'.
} 


\section{REFERÊNCIAS}

BADECKER, W.; STRAUB, K. The Processing Role of Structural Constraints on the Interpretation of Pronouns and Anaphors. Journal of Experimental Psychology: Learning, Memory, and Cognition, v. 28, n. 4, 2002, p. 748-769.

BERTOLINO, K. G.; GROLLA, E.O pronome "ele" está sujeito ao princípio B? Uma discussão sobre os resultados experimentais. Revista Linguística/ Revista do Programa de Pós-Graduação em Linguística da Universidade Federal do Rio de Janeiro. Volume 8, número 2, dezembro de 2012.

BRITO, D. B. S. Predicados reflexivos e compartilhamento de traços. Estudos Linguísticos, São Paulo, v. 40, p. 220-230, $2011 \mathrm{a}$.

$2011 \mathrm{~b}$.

Propriedades Referenciais do Reflexivo SE no Português Brasileiro. Leitura, UFAL, v. 1, p. 92-108,

; SILVA, C. R. T. . Teoria da Vinculação. In: FERRARI-NETO, J.; SILVA, C. R. T. (Orgs.).

Programa Minimalista em foco: princípios e debates. Curitiba: CRV, 2012. v. 1; p. 197-216.

CAMACHO, R. G. Em defesa da categoria de voz média no português. DELTA, v. 19, n. 1, 2003, p. 91-122.

CARVALHO, G. C. Um estudo descritivo dos predicadores experienciais psicológicos, físicos, epistêmicos e de percepção do português: análise das correlações sintático-semânticas orientada pela frequência dos tipos de construções morfológicas. 2008. 167 f. Dissertação (Mestrado em Lingüística) - Faculdade de Letras, UFMG, Belo Horizonte.

CHOMSKY, N. Lectures on government and binding. Dordrecht: Foris 1981.

Barriers. Linguistic Inquiry, n.13, 1986.

CLIFTON, C.; KENNISON, S. M.; ALBRECHT, J. E. Reading the words him and her: Implications for parsing principles based on frequency and on structure. Journal of memory and language, v. 36, 276-292, 1997.

COHEN, J.; MaCWHINNEY, B.; FLATT, M.; PROVOST, J. An interactive graphical system for designing and controlling experiments in the psychology laboratory using Macintosh computers. Behavior methods, research, instruments, and computers, v. 25, p. 257-271, 1993.

D'ALBUQUERQUE, A.C.R.C. A perda dos clíticos num dialeto mineiro. Tempo brasileiro, ns. 78/79, p. 97121,1984 .

ESTRELA, A. A. Teoria da Ligação: dados do português europeu. Dissertação (Mestrado em Linguística) Faculdade de Ciências Sociais e Humanas, Universidade Nova de Lisboa, 2006.

GALVES, Charlotte. Ensaios sobre as gramáticas do português. Campinas: Editora da UNICAMP, 2001.

GARROD, S. C.; SANFORD, A. J. Resolving sentences in a discourse context. In: GERNSBARCHER, Morton A. (Ed). Handbook of Psycholinguistics. New York: Academic Press, 1994. p. 675-698.

GROLLA, E.; BERTOLINO, K. A proforma 'ele' com antecedente local em português brasileiro adulto e infantil. In: HORA, D. da; NEGRÃO, E. Estudos da Linguagem: casamento entre temas e perspectivas. João Pessoa: Editora Ideia; Editora Universitária da UFPB, 2011.

KAISER, E. The quest for a referent: a crosslinguistic look at reference resolution. Ph.D. dissertation. University of Pennsylvania, Philadelphia, PA, 2003.

; TRUESWELL J. Interpreting pronouns and demonstratives in Finnish: evidence for a formspecific approach to reference resolution. Language and cognitive processes, v. 23, n. 5, p. 709-748, 2008.

KENNISON, S. Comprehending the pronouns her, him, and his: implications for theories of referential processing. Journal of memory and language, v. 49, p. 335-352, 2003.

LEITÃO, M. M.; PEIXOTO, P.; SANTOS, S. Processamento da co-referência intra-sentencial em português brasileiro. Veredas on-line, v. 2, p. 50-61, 2008.

LEMLE, M. Análise sintática: teoria geral e descrição do português. São Paulo: Ática, 1984. 
MENUZZI, S. Binding theory and pronominal anaphora in Brazilian Portuguese. Dissertation (PHD in Linguistics) - Leiden University, 1997.

MELO, N. D. S. O clítico "se" com valor reflexivo ou reciproco: uma abordagem sociolinguística. 2005. 123 f. Tese (Mestrado em Linguística) - Universidade Federal de Uberlândia, 2005.

NICOL, J.; SWINNEY, D. The role of structure in coreference assignment during sentence comprehension. Journal of Psycholinguistic research. v. 18, n. 1, p. 5- 19, 1989.

NUNES, J. Ainda o famigerado "se". DELTA, v.11, n.2, p. 201-240,1995.

. Direção de cliticização, objeto nulo e pronome tônico na posição de objeto em português brasileiro. In: KATO, M.; ROBERTS, I. (Orgs). Português brasileiro: uma viagem diacrônica. 2. ed. Campinas: EDUNICAMP, 1996.

OLIVEIRA, M. de. Nós se cliticizou-se? In: LOBO, T.; RIBEIRO, I.; CARNEIRO, Z.; ALMEIDA, N. (Orgs). Para a história do português brasileiro: novos dados, novas análises. V. VI. Salvador: Ed. UFBA, 2006.

OLIVEIRA, R. C.; LEITÃO, M. M.; HENRIQUE, J. G. A influência dos antecedentes vinculados e não vinculados no processamento da anáfora a si mesmo(a). Linguística, Rio de Janeiro, v. 8, p. 71-85, 2012.

POLLARD C, SAG I. Anaphors in English and the scope of Binding Theory. Linguistic inquiry, v. 23, p. 261-303, 1992.

REINHART, T.; REULAND, E. Reflexivity. Linguistic inquiry, v. 24, n. 4, p. 657-720, 1993.

REULAND, E. Primitives of binding. Linguistic inquiry, v. 32, p. 439-492, 2001.

RIBEIRO, A. J. C.A abordagem good-enough e o processamento de frases do português do Brasil. Veredas on-line, v [?], n. [?], p. 62-75, 2008.

RIBEIRO, P. A alternância causative no Português do Brasil: a distribuição do clítico SE. Dissertação (Mestrado em Letras) - Universidade Federal do Rio Grande do Sul, Porto Alegre, 2010.

STURT, P. The time-course of the application of binding constraints in reference resolution. Journal of memory and language, v. 48, p. 542-562, 2003.

WOLF F, GIBSON E, DESMET T. Discourse coherence and pronoun resolution. Language and cognitive processes, v. 19, p. 665-675, 2004.

Recebido em 12/07/2014. Aprovado em 28/09/14. 